\title{
Fielding of a time-resolved tomographic diagnostic
}

\author{
Daniel Frayer*, Brian Cox, Wendi Dreesen, Douglas Johnson, Mike Jones, Morris Kaufman \\ National Security Technologies, LLC, Los Alamos Operations, 182 East Gate Drive, \\ Los Alamos, NM 87544
}

\begin{abstract}
A diagnostic instrument has been developed for the acquisition of high-speed time-resolved images at the Dual-Axis Radiographic Hydrodynamic Test (DARHT) Facility at Los Alamos National Laboratory. The instrument was developed in order to create time histories of the electron beam. Four discrete optical subsystems view Cerenkov light generated at an x-ray target inside of a vacuum envelope. Each system employs cylindrical optics to image light in one direction and collapse light in the orthogonal direction. Each of the four systems images and collapses in unique axes, thereby capturing unique information. Light along the imaging axis is relayed via optical fiber to streak cameras. A computer is used to reconstruct the original image from the four optically collapsed images. Due to DARHT's adverse environment, the instrument can be operated remotely to adjust optical parameters and contains a subsystem for remote calibration. The instrument was deployed and calibrated, and has been used to capture and reconstruct images. Matters of alignment, calibration, control, resolution, and adverse conditions will be discussed.
\end{abstract}

Keywords: fielding, tomography, adverse environment, instrumentation, high-speed imaging

\section{INTRODUCTION}

Kaufman et al. (2006) ${ }^{1}$ describe the design considerations for the development of a time-resolved diagnostic system for use at the Dual-Axis Radiographic Hydrodynamic Test (DARHT) Facility at Los Alamos National Laboratory. This design has been finalized and the diagnostic instrument fabricated, calibrated and fielded with good results.

In brief, the DARHT facility is designed to record high-speed radiographic images of explosively driven hydrodynamic events. This is accomplished by the illumination of a test object with $\mathrm{x}$-ray pulses occurring within a $2-\mu$ s envelope and the recording of the resulting radiographic images. These x-ray pulses are generated by illuminating $\mathrm{x}$-ray converter targets with high-power electron beams along two orthogonal axes.

The tomographic instrument was developed to create time histories of the DARHT electron beam when the DARHT second axis was being commissioned. Four discrete optical subsystems view, through a 6-inch window in a pump cross, Cerenkov light generated by the beam incident upon a thin $(200-500 \mu \mathrm{m}), 5$-inch-diameter $\mathrm{x}$-ray target inside of the vacuum envelope. Each system employs cylindrical optics to image light in one direction and collapse light in the orthogonal direction. Each of the four systems images and collapses in unique axes, thereby capturing unique information. Light along the imaging axes is relayed via optical fiber arrays and is recorded by streak cameras coupled to CCDs, resulting in temporal resolution of $2 \mathrm{~ns}$ over a recording window of $2 \mu \mathrm{s}$. Computer software then reconstructs a two-dimensional time history of the electron beam from the four optically collapsed one-dimensional (1-D) histories.

Two versions of this diagnostic have been built and fielded: a two-view system with just two optical lines of sight, as described by Bender et al. (2007) ${ }^{2}$ and used in early stages of DARHT commissioning ${ }^{3,4,5,6,7,8}$, and an earlier four-view system ${ }^{9}$. Both systems were fielded at DARHT in easily accessible, low-environmental-risk areas. This third-generation diagnostic was designed to be fielded in an area with restricted access and higher environmental risk, and to have the ability to change optical parameters during experiments. Although the optical design is similar to that of its predecessors, this system is necessarily more complex as it includes remote calibration, and electronic and motion control functions.

* frayerdk@nv.doe.gov; phone 1505 663-2090; fax 1505 663-2003; nstec.com 


\section{SYSTEM DESCRIPTION}

A list of functional requirements is shown in Table 1; some general operating requirements are in Table 2; and calibration requirements are in Table 3. Technical reasons for the calibration requirements are discussed in Section 3.

Table 1. Functional requirements.

\begin{tabular}{|c|c|c|}
\hline Quantity & Specification & Comments \\
\hline 1. Position accuracy & $\pm 10 \%$ of radius & Radius is expected to be 1 to $5 \mathrm{~cm}$. \\
\hline 2. RMS radius accuracy & $\pm 10 \%$ of radius & Radius is expected to be 1 to $5 \mathrm{~cm}$. \\
\hline 3. Ellipticity accuracy & Better than $10 \%$ & $\begin{array}{l}\text { Ellipticity here is defined as the ratio of the } \\
\text { minor axis to the major. }\end{array}$ \\
\hline 4. Field of view (FOV) & $>132 \mathrm{~mm}$ & $\begin{array}{l}\text { This is only the case when lenses are } \\
\text { zoomed out to view the whole target. }\end{array}$ \\
\hline 5. Resolution & $>1.05 \mathrm{lp} / \mathrm{mm}$ at the target & $\begin{array}{l}\text { This requirement, derivative of nos. } 1-3 \text {, is } \\
\text { only the case when zoomed in to view the } \\
\text { minimum beam size. }\end{array}$ \\
\hline 6. Depth of field & $\begin{array}{l}>93.3 \mathrm{~mm} \text { zoomed out } \\
>37.5 \mathrm{~mm} \text { zoomed in }\end{array}$ & $\begin{array}{l}\text { Sufficient to image the entire target tilted } \\
\text { at } 45^{\circ} \text {. }\end{array}$ \\
\hline 7. Temporal resolution & $2 \mathrm{~ns}$ & \\
\hline
\end{tabular}

Table 2. General operating requirements.

\begin{tabular}{|c|c|c|}
\hline Quantity/Requirement & Specification & Comments \\
\hline 1. Remote adjustment of zoom & Lens minimum to $132 \mathrm{~mm}$ FOV & Across the whole field. \\
\hline 2. Remote adjustment of focus & $18^{\prime \prime}$ to infinity & \\
\hline $\begin{array}{l}\text { 3. Remote adjustment of } \\
\text { aperture }\end{array}$ & $\begin{array}{l}\text { Lens maximum to } \mathrm{f} / 32 \text {, in a minimum } \\
\text { of } 8 \text { steps }\end{array}$ & $\begin{array}{l}\text { Maximum varies from } \mathrm{f} / 3.5 \text { to } 5.6 \text { based } \\
\text { on zoom. }\end{array}$ \\
\hline 4. Remote calibration of system & - & $\begin{array}{l}\text { This requires a mirror to change the view } \\
\text { from beam target to calibration system. }\end{array}$ \\
\hline 5. Repeatability & $\begin{array}{l}\text { Repeatability for zoom and focus of } \\
\text { better than resolution at the target }\end{array}$ & $\begin{array}{l}\text { This necessitates limit switches for both } \\
\text { adjustments. }\end{array}$ \\
\hline
\end{tabular}

Table 3. Calibration requirements.

\begin{tabular}{|l|l|l|}
\hline Test & Specification & Comments \\
\hline 1. Flat field & $>95 \%$ uniformity & Across the whole field. \\
\hline 2. Dark field & $>99 \%$ of light blocked & Achieved with interoptic shutters. \\
\hline 3. Scaling & $>5$ resolution lines & $\begin{array}{l}\text { Two stripe patterns with differing } \\
\text { predetermined periods for maximum and } \\
\text { minimum required magnifications are used } \\
\text { to determine exact scaling factors for } \\
\text { reconstruction. }\end{array}$ \\
\hline 4. Orientation & $\begin{array}{l}\text { All imaging axes must remain constant } \\
\text { across imaging runs }\end{array}$ & $\begin{array}{l}\text { A pattern of LEDs is used to determine that } \\
\text { the fiber arrays have correct orientation. }\end{array}$ \\
\hline 5. Rotation & $\begin{array}{l}>270^{\circ} \text { rotation of calibration stage with } \\
\text { targets, with high accuracy, resolution and } \\
\text { repeatability }\end{array}$ & $\begin{array}{l}\text { Resolution and repeatability should be } \\
\text { better than } 0.1^{\circ} \text {. Accuracy should be better } \\
\text { than } 1^{\circ} .\end{array}$ \\
\hline
\end{tabular}

The diagnostic system consists of: 1) an automated optical instrument (or lens assembly) for capturing 1-D data; 2) a system, including fiber-optic arrays and streak cameras, for relaying and recording the 1-D data; 3 ) an automated system (including the calibration assembly) for calibrating the optical instrument; and 4) control computers and electronics. A system-level diagram can be found in Kaufman et al. ${ }^{1}$

The heart of the lens assembly is four single-axis gimbals mounted in a common plate. The gimbals hold the four lenses as close together as possible, while leaving room for the motorized actuators. The gimbals are mounted using flexural bearings and are positioned with micrometers that allow for an adjustable viewing angle for mastering purposes and for alignment with the facility after installation. 


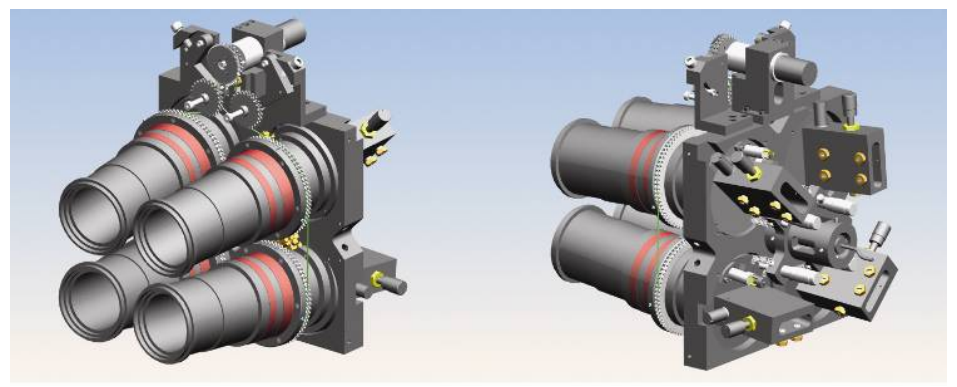

Fig. 1: Two views of the lens assembly.

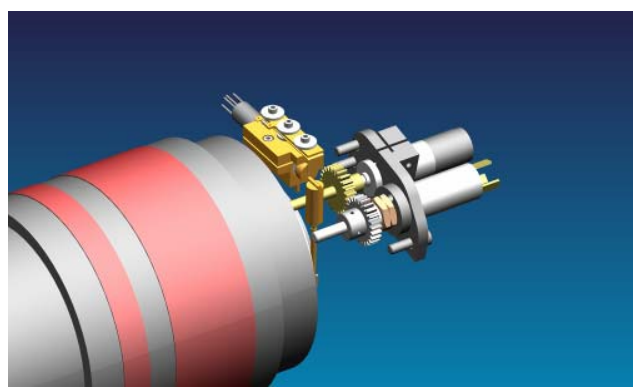

Fig 2: Focus and aperture assembly.

All remote adjustments in the lens assembly, made as described in Kaufman et al. ${ }^{1}$, are summarized in Table 4. Design images of the lens assembly are shown in Figure 1; the focus and aperture subassembly is shown in Figure 2.

Table 4. Summary of remote adjustments.

\begin{tabular}{|l|l|l|}
\hline Adjustment & Actuation & Comments \\
\hline 1. Focus & $\begin{array}{l}\text { Via actuation of the autofocus mechanism, using miniature stepper } \\
\text { motors with planetary gearboxes. }\end{array}$ & Individually controlled. \\
\hline 2. Aperture & $\begin{array}{l}\text { Via actuation of each lens's aperture lever by similar motor- } \\
\text { gearbox assemblies with cam/push-rod combination mechanisms. }\end{array}$ & Individually controlled. \\
\hline 3. Zoom & Via common 3-d belt drive. & $\begin{array}{l}\text { Optical zoom for all four lenses is } \\
\text { controlled and actuated simultaneously. }\end{array}$ \\
\hline
\end{tabular}

Tomographic reconstruction of the compressed images drives the requirements for calibration. Dark levels are not flat across streak images; therefore, dark-field images are used to create a subtractive baseline. Streak images also exhibit geometric distortion; timing combs, outside of the FOV passed by the lenses, help to correct this distortion. As differences in transmission between fibers and whole arrays can introduce artifacts into the reconstructions, flat-field images are needed to obtain actual relative transmission values. Because variations in magnification exist between lens subassemblies, resolution patterns of known period are required to properly scale data from each of the four lenses.

The calibration assembly light source is a commercial off-the-shelf photographic flash lamp. This lamp sits at the bottom end of a cylinder and the object/illumination plane is at the top. Several holographic diffusers are situated between these, with engineered diffusion angles designed to give as flat illumination as possible at the object/illumination plane.

Calibration is performed by 1) rotating the mirror so as to view the calibration assembly, and then 2) imaging the illumination plane in the calibration assembly. In the ground state of the subsystem, a flat-field target lies in this plane. For the scaling test, a resolution target is placed atop this flat-field target via a flipper mechanism; LEDs for determining orientation lie on the flipped mount for the resolution target, outside of the normal operating FOV. The entire calibration assembly rotates into alignment with the imaging axis of a given imaging lens subassembly.

Several modifications were made to the conceptual design proposed in Kaufman et al. ${ }^{1}$ To accommodate tough environmental conditions the optical system folds by way of a single mirror to better protect optics and electronic components from radiation damage. Making this mirror a kinematically mounted rotating mirror allows the stationary lens assembly to view either the Cerenkov target or the calibration target. This provides additional advantages, such as the absence of a complex strain-relief mechanism for a rotating lens assembly, but also results in the slight disadvantages of a larger overall footprint and a longer object distance. In order to minimize misalignment and mastering time during installation, the mechanical stand for the optical system was designed to mount directly to the facility weldment holding the viewing window's pump cross. A photograph of the assembled system is shown in Figure 3, with major components labeled.

A motor control system was required for the remote operation of the optical instrument's zoom, focus, aperture, and calibration controls. The system was divided mechanically into two parts: the lens assembly control and the calibration control. The lens and calibration assemblies are located on the DARHT second-axis beam line in a small, nonenvironmentally controlled temporary shelter in front of the accelerator hall. Because they are exposed to radiation when the beam is operating, no integrated circuits are installed in these assemblies. The control system is located $\sim 40$ feet 
away, and the electrical control lines are fed through conduit into the main DARHT building where the control room resides. The operator controls the system via Ethernet from the DARHT control room.

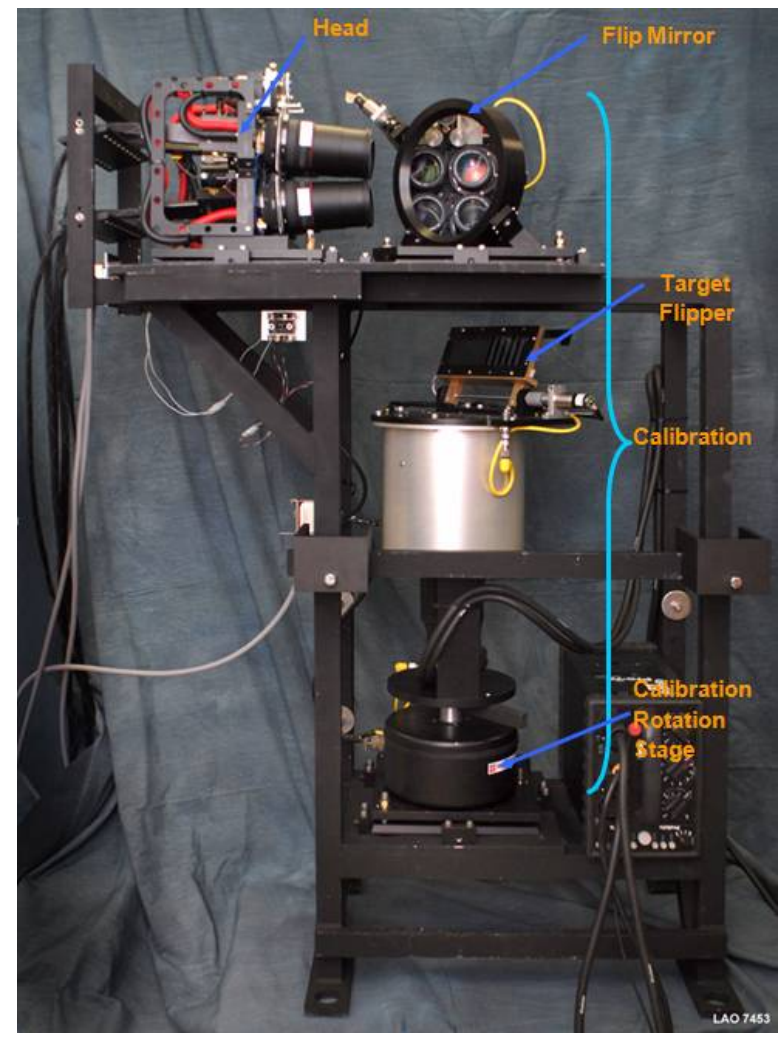

Fig. 3. The assembled lens and calibration system.

Two six-axis motor controllers manage the various motors: one handles the lens assembly motors including zoom, aperture, and focus, utilizing all six axes; the other handles the calibration controllers, target flipper, mirror flipper, and calibration rotation. Two custom printed circuit boards (PCBs) were designed to enable communication in the system: one converts voltages from potentiometers to a quadrature signal, and the second facilitates the connection of all motors, drivers, digital $\mathrm{I} / \mathrm{O}$ and encoder PCBs.

Motor system control is accomplished through software architecture utilizing Adobe Flash and a small Python Web server with a hardware language translator. The Python script, programmed on the compact flash card of a PC/104, runs a small Web server and communicates to the motor controllers via Ethernet sockets. The Flash user interface also resides on the PC/104. When the operator presses buttons and enters information from the Web page, requests are encoded into URL requests sent to the Python script where they are translated into native calls to the appropriate controllers. The Flash player keeps a persistent connection open to PC/104, so as the XML status file is updated, those changes are reflected immediately back to the Web page, resulting in nearly real-time feedback. The benefits to this scheme are that the system is independent of any attached computer (because the Web page is generated by the hardware) and the control system can be accessed from any network computer.

\section{CHARACTERIZATION AND QUALIFICATION}

Before fielding, the entire diagnostic system was assembled, tested, and characterized to ensure compliance with the requirements as listed above.

Locking adjustments were included for six degrees of freedom for the lens assembly, mirror assembly, and calibration system to ensure proper alignment after initial setup. Single-degree-of-freedom locking adjustments were also included for the fiber arrays at the lens end to ensure proper boresiting. An alignment laser with six degrees of freedom was installed in the center of the lens assembly for boresiting. 
The initial mastering step was to adjust the alignment laser to be perpendicular to the plate holding the optical components. This was done by mounting the assembly and a 1-m rail to an optical table, affixing an aperture to the rail and sliding the aperture along the length of the rail, while adjusting the laser to ensure clearance through the aperture. The fibers were then seated in the assembly and back-lit; their exact position was adjusted to ensure centration of the four array images about the position of the laser at the imaging plane of the lenses. The results are shown in Figure 4.

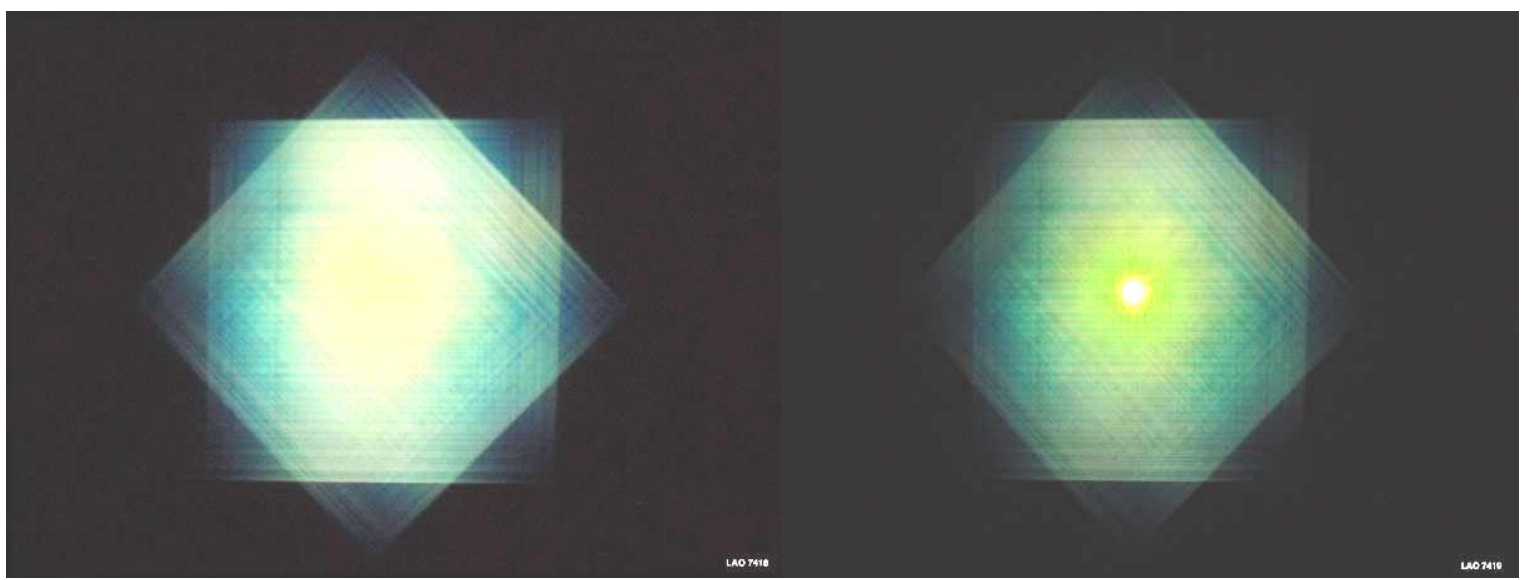

Fig. 4: Concentration of the four array images, without (left) and with alignment laser (right).

Exact resolution, and thereby compliance with functional requirements nos. 1 and 2 (Table 1), was determined by dividing the number of resolution elements in each array image (192 fibers $=96$ elements) by each image's extent in the imaging direction. Resolution results are shown in Table 5.

Table 5. Resolution.

\begin{tabular}{|c|c|c|}
\hline Lens & FOV (mm) & Resolution (lp/mm) \\
\hline 1 & 53.1 & 1.81 \\
\hline 2 & 53.2 & 1.80 \\
\hline 3 & 54.4 & 1.76 \\
\hline 4 & 54.3 & 1.77 \\
\hline
\end{tabular}

Functional requirements nos. 1 and 2, i.e., accuracy in the determination of position and RMS radius, dictate a minimum resolution of $1 \mathrm{lp} / \mathrm{mm}$ : as can be seen in Table 5, the system was determined to meet these requirements. For functional requirement no. 3 , accuracy in the determination of ellipticity, an elliptical beam with an average radius of $1 \mathrm{~cm}$ and an ellipticity of 0.9 has radii $\mathrm{r}_{\mathrm{a}} \approx 1.05$ and $\mathrm{r}_{\mathrm{b}} \approx 0.95$, thus dictating a minimum resolution of $1.05 \mathrm{lp} / \mathrm{mm}$. All four imaging subsystems can be seen have met this resolution requirement as well (Table 5).

Additionally, a $20-\mathrm{mm}$ ellipse was placed atop the flat-field target at various rotations and imaged with the system; software reconstructions verify that $90 \%$ ellipticity is well within the measurement capabilities of this instrument when fully zoomed in, and may even be determined when operating at lower magnifications. Results of the reconstruction routine may be seen in Figure 5.

The four lenses were zoomed in and out over the full extent allowable by the limit switches and were determined to have an average FOV of $53.75 \mathrm{~mm}$ (zoomed in) and $184 \mathrm{~mm}$ (zoomed out) (Figure 6), meeting the maximum required FOV of $132 \mathrm{~mm}$.

Two facts were determined to have consequences on the fielding of the instrument: 1) zoom and focus are nonlinearly coupled, as shown in Figure 7, and 2) the optical zoom as a function of potentiometer reading has considerable hysteresis that varies between lenses. The former meant that a chart relating FOVs to focus position, based on measurements, would be needed to field the device. The latter finding meant that when adjusting the zoom, the lenses would first have to be fully zoomed in to negate the backlash and rezero the system. 
Reconstructions RMS Radius x-y Zoomed In

10-26-07
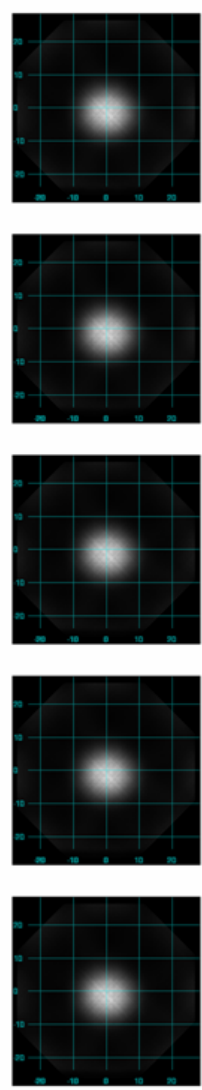
Background 5\% of Peak Excluded

Reconstruction 01

width $=5.306$

height $=4.429$

$\mathrm{h} / \mathrm{w}=0.83$

Reconstruction 02

width $=4.497$

height $=3.845$

$\mathrm{h} / \mathrm{w}=0.86$

width $=3.617$

height $=3.268$

$\mathrm{h} / \mathrm{w}=0.90$

major $=24.7090$

minor $=22.2327$

ratio $=0.90$

Reconstruction 03

width $=3.851$

height $=3.490$

$\mathrm{h} / \mathrm{w}=0.91$

width $=3.335$

height $=3.005$

$\mathrm{h} / \mathrm{w}=0.90$

major $=24.6606$

minor $=22.1878$

ratio $=0.90$

Reconstruction 04

width $=4.545$

height $=3.855$

$\mathrm{h} / \mathrm{w}=0.85$

width $=3.617$

height $=3.266$

major $=24.6299$

minor $=22.1641$

$\mathrm{h} / \mathrm{w}=0.90$

ratio $=0.90$

Reconstruction 05

width $=4.920$

height $=4.136$

$\mathrm{h} / \mathrm{w}=0.84$ width $=3.692$

height $=3.347$

$\mathrm{h} / \mathrm{w}=0.91$ major $=24.6246$

minor $=22.1875$

ratio $=0.90$

Fig. 5. Reconstructed ellipses from the zoomed-in configuration.

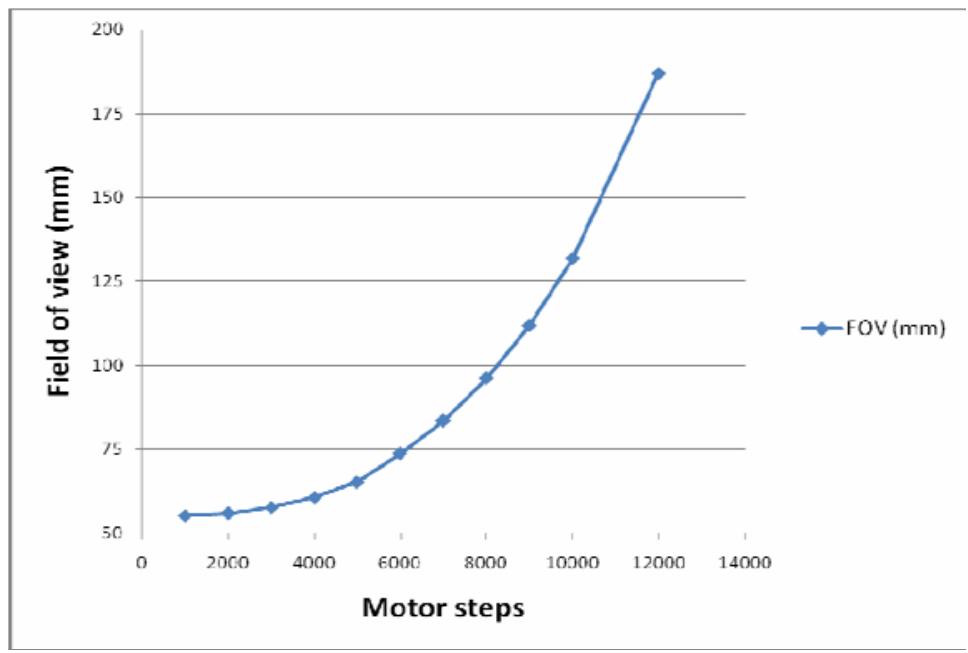

Fig. 6. Average field of view as a function of motor steps. 


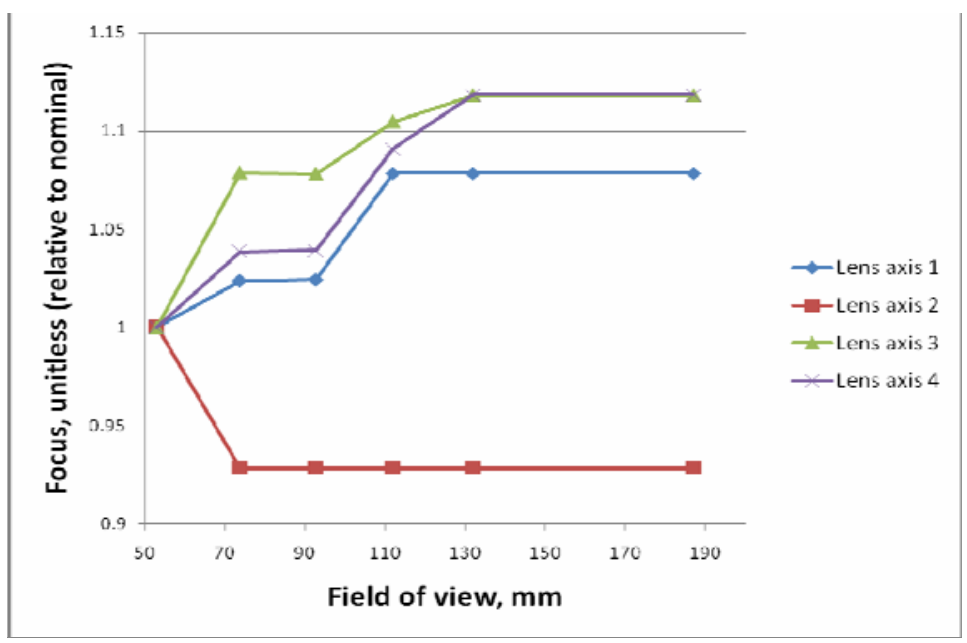

Fig. 7. Focus as a function of field of view.

As a final imaging test, each lens was tested to determine depth of field for wide-open aperture. This was greatly simplified by the fact that the individual fibers in each array are visible at the back-lit image plane. The data are shown in Table 6.

Table 6. Depth of field for optical axes.

\begin{tabular}{|c|c|c|}
\hline Lens & Field depth, zoomed in (mm) & Field depth, zoomed out (mm) \\
\hline 1 & 50 & 345 \\
\hline 2 & 90 & 400 \\
\hline 3 & 50 & 180 \\
\hline 4 & 45 & 230 \\
\hline
\end{tabular}

The depth-of-field requirements of at least $37.5 \mathrm{~mm}$ zoomed in and $93.3 \mathrm{~mm}$ while zoomed out (Table 1) were met by the instrument despite considerable differences in depth of field between lenses. As temporal resolution is determined by the streak camera, the instrument was qualified as meeting all functional requirements.

All of the operating requirements listed in Table 2 were engineered into the system. The only ones requiring verification were high repeatability in zoom and focus, both of which were determined in the positive to be considerably better than the system's resolution limits.

The flat-field calibration target requirement of $>95 \%$ flatness (calibration requirement no. 1) was demonstrated by: 1) determining flatness for a separate imaging camera through the use of an integrating sphere; 2) fixing a filter matching the sensitivity curve of the combination of the fiber array and the streak camera to the imaging camera; 3 ) measuring the flat-field target with the camera with an object distance equivalent to that of the four lenses in the lens assembly; and 4) making iterative adjustments of filters and diffusers in the calibration illumination source and flat-field target. Flatness data are shown in Figure 8. Note that the flat-field target is larger than the maximum FOV used for data collection $(132 \mathrm{~mm})$, and as such, the severe roll-off at the edges can be ignored.

The calibration requirement to block $>99 \%$ of light (Table 3, no. 2) was verified by 1) assembling the system as designed (i.e., not in the back-lit configuration); 2) placing a bright light source at the object plane; and 3) closing the shutters on each axis and measuring light using the streak cameras at their slowest setting. Scaling (Table 3, no. 3) was engineered, as was verification of orientation (Table 3, no. 4) by LEDs at the illumination plane of the calibration assembly, outside of the maximum FOV used for data collection; during calibration, the lenses must operate at an FOV greater than $132 \mathrm{~mm}$. The LEDs are arranged such that they produce unambiguous patterns at the streak camera, and these patterns determine the orientation of fibers. 


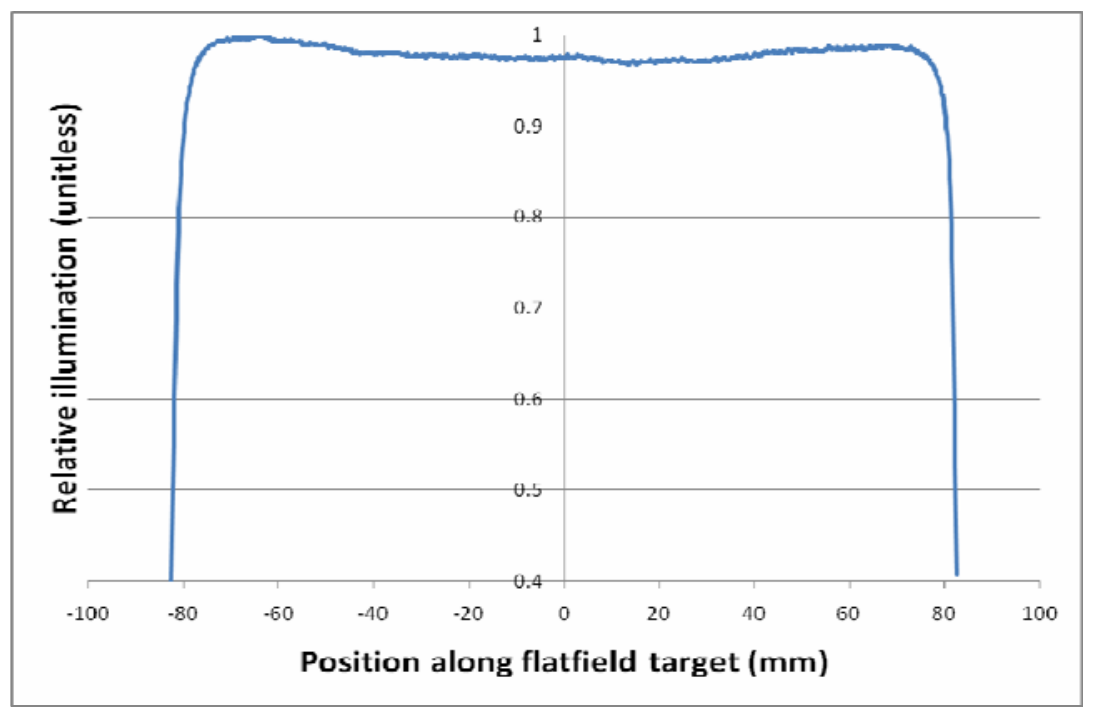

Fig. 8. Flat-field illumination.

The calibration specification for $270^{\circ}$ rotation of calibration stage with targets, with high accuracy, resolution and repeatability (Table 3, no. 5), was verified by mounting a mirror to the calibration stage and reflecting a laser from it. The angle of reflection was repeatedly measured via a long lever arm, and accuracy, resolution and repeatability were all determined as very good.

\section{FIELDING AND INTEGRATION}

The diagnostic assembly was fixed directly to the weldment holding the pump cross, and the distances from the vacuum window to the mirror and the mirror to the mounting plate were measured to verify rough correlation with models. The major optical components of the assembly, namely, the lens assembly, the mirror, and the calibration assembly, were attached to the frame by means of three stages giving six degrees of freedom. With the alignment laser turned on and the x-ray target withdrawn, two reflections each from the two windows on either side of the pump cross were generated. Reticules with small clearance apertures were centered on these two windows. The three tip-tilt stages were adjusted iteratively to align the laser: the size of the grouped retro-reflected beams was minimized to obtain a perpendicular angle, and the laser was directed through both apertures to obtain centration in the pump cross. Both approaches were necessary because of mechanical tolerances of the pump cross and viewing windows.

A mask containing an ellipse was positioned at various points in the flat-field aperture and imaged; orientation assumptions in the reconstruction algorithm were validated by these reconstructions. Additionally, a full suite of calibration tests was remotely performed to work through control issues and to verify maintenance of mastering and alignment after installation.

\section{EXPERIMENTAL RESULTS}

The four-view diagnostic was successfully fielded on DARHT experiments over the course of several weeks. The accuracy of reported size, shape and position of the beam as derived from reconstructions was verified by data from beam position monitors and images from a gated framing camera. A single frame from the reconstruction can be seen in Figure 9a, and compared against an image from the gated framing camera, taken at the same time as the frame in 9a, in Figure $9 \mathrm{~b}$. Note that the reconstructed frame has been flipped for qualitative comparison, as the framing camera captured an image from the back side of the target. 


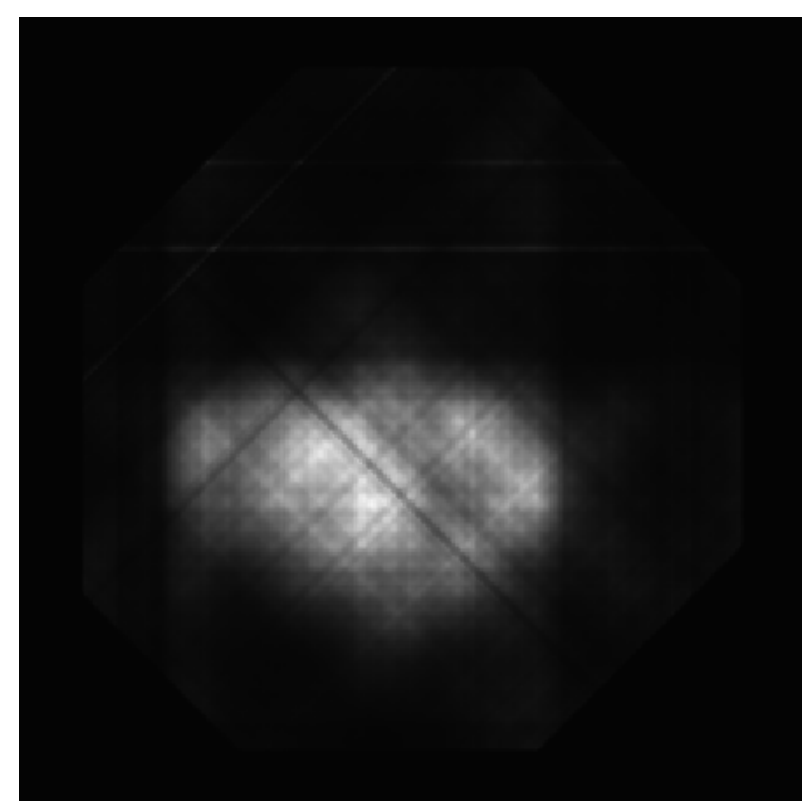

Figure 9a. A reconstructed frame.

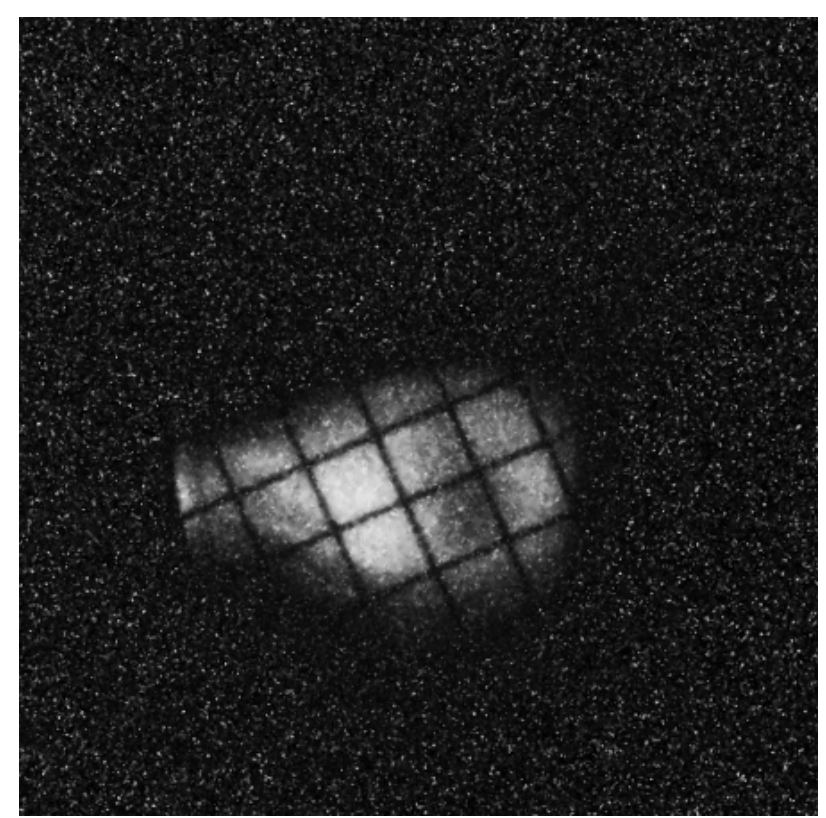

Figure $9 \mathrm{~b}$. An image from the gated framing camera.

\section{CONCLUSIONS}

The dynamic 4-view system has been fabricated, assembled and tested, and is now installed and fully operational at the second axis of DARHT. The system has been found to meet or exceed primary driver and secondary requirements. Data from this diagnostic have been verified by existing diagnostic instrumentation, and have proven useful in determining static beam parameters as well as observing dynamic beam evolution. Unlike the previous 4-view system, this system was designed and built for a harsh environment with difficult infrequent access, having completely remote calibration capability, as well as remote zoom, focus and aperture control. The dynamic 4-view system is a unique tool for DARHT experimentation. 


\section{ACKNOWLEDGMENTS}

This manuscript has been authored by National Security Technologies, LLC, under Contract No. DE-AC52-06NA25946 with the U.S. Department of Energy. The United States Government retains and the publisher, by accepting the article for publication, acknowledges that the United States Government retains a non-exclusive, paid-up, irrevocable, worldwide license to publish or reproduce the published form of this manuscript, or allow others to do so, for United States Government purposes.

\section{REFERENCES}

[1] Kaufman, M., Frayer, D., Dreesen, W., Johnson, D., and Meidinger, A., "Design considerations for a timeresolved tomographic diagnostic at DARHT," Proc. SPIE 6289, 2006).

[2] Bender, H., Carlson, C., Frayer, D., Johnson, D., Jones, K., Meidinger A., Ekdahl, C., "Quasianamorphic optical imaging system with tomographic reconstruction for electron beam imaging," Rev. Sci. Instrum. 78(1), 013301 (2007).

[3] Ekdahl, E., Abeyta, O., Bender, H., Broste, W., Carlson, C., Caudill, L., Chan, K. C. D., Chen, Y. J., Dalmas, D., Durtschi, G., Eversole, S., Eylon, S., Fawley, W., Frayer, D., Gallegos, R., Harrison, J., Henestroza, E., Holzscheiter, M., Houck, T., Hughes, T., Jacquez, E., Johnson, D., Johnson, J., Jones, K., McCuistan, B. Trent, Meidinger, A., Montoya, N., Mostrom, C., Moy, K., Nielsen, K., Oro, D., Rodriguez, L., Rodriguez, P., Sanchez, M., Schauer, M., Simmons, D., Smith, H. V., Studebaker, J., Sturges, R., Sullivan, G., Swinney, C., Temple, R., Tom, C. Y., and Yu, S. S., "First beam at DARHT-II," Proc. of the 2004 Particle Accelerator Conference, 558$562(2003)$.

[4] (EPAC04) 1497-1499 (2004).

[5] Ekdahl, E., Abeyta, O., Bartsch, R., Bender, H., Briggs, R., Broste, W., Carlson, C., Caudill, L., Chan, K. C. D., Chen, Y. J., Dalmas, D., Durtschi, G., Eversole, S., Eylon, S., Fawley, W., Frayer, D., Gallegos, R., Harrison, J., Henestroza, E., Holzscheiter, M., Houck, T., Hughes, T., Jacquez, E., Johnson, D., Johnson, J., Jones, K., McCuistan, B. Trent, Meidinger, A., Montoya, N., Mostrom, C., Moy, K., Nath, S., Nielsen, K., Oro, D., Rodriguez, L., Rodriguez, P., Rowton, L., Sanchez, M., Scarpetti, R., Schauer, M., Simmons, D., Smith, H. V., Studebaker, J., Sturges, R., Sullivan, G., Swinney, C., Tang, Y., Temple, R., Tipton, A., Tom, C. Y., and Yu, S. S., "DARHT-II long-pulse beam-dynamics experiments," Proc. of the 2005 IEEE Particle Accelerator Conference, 1252-1255 (2005).

[6] Ekdahl, C., "Aliasing errors in measurements of beam position and ellipticity," Rev. Sci. Instrum. 76, 095108 (2005).

[7] Ekdahl, E., Abeyta, E. O., Bender, H., Broste, W., Carlson, C., Caudill, L., Chan, K. C. D., Chen, Y. J., Dalmas, D., Durtschi, G., Eversole, S., Eylon, S., Fawley, W., Frayer, D., Gallegos, R., Harrison, J., Henestroza, E., Holzscheiter, M., Houck, T., Hughes, T., Humphries, S., Johnson, D., Johnson, J., Jones, K., Jacquez, E., McCuistan, B. Trent, Meidinger, A., Montoya, N., Mostrom, C., Moy, K., Nielsen, K., Oro, D., Rodriguez, L., Rodriguez, P., Sanchez, M., Schauer, M., Simmons, D., Smith, H.V., Studebaker, J., Sturges, R., Sullivan, G., Swinney, C., Temple, R., Tom, C. Y., and Yu, S. S., "Initial electron-beam results from the DARHT-II linear induction accelerator," IEEE Trans. Plasma Sci., 33(2, pt. 3) 892-900 (2005).

[8] Ekdahl, E., Abeyta, E. O., Aragon, P., Archuleta, R., Bartsch, R., Bender, H., Briggs, R., Broste, W., Carlson, C., Chan, K. C. D., Dalmas, D., Eversole, S., Frayer, D., Gallegos, R., Harrison, J., Hughes, T., Jacquez, E., Johnson, D., Johnson, J., McCuistan, B. Trent, Montoya, N., Mostrom, C., Nath, S., Oro, D., Rowton, L., Sanchez, M., Scarpetti, R., Schauer, M., Schulze, M., Tang, Y., Tipton, A., and Tom, C. Y., "Long-pulse beam stability experiments on the DARHT-II linear induction accelerator," IEEE Trans. Plasma Sci., 34(2, pt. 3) 460-466 (2006).

[9] Ekdahl, E., Abeyta, E. O., Aragon, P., Archuleta, R., Bartsch, R., Bender, H., Broste, W., Carlson, C., Dalmas, D., Eversole, S., Frayer, D., Gallegos, R., Harrison, J., Jacquez, E., Johnson, D., Johnson, J., McCuistan, B. Trent, Montoya, N., Nath, S., Oro, D., Rowton, L., Sanchez, M., Scarpetti, R., Schauer, M., Seitz, G., Tipton, A., and Tom, C. Y., "Commissioning the DARHT-II scaled accelerator," Proc. of the 2007 Particle Accelerator Conference, 2373-5 (2007). 